\title{
Cosmopolitanism, Custom, and Complexity: Kant's Cosmopolitan Norms in Action
}

\author{
Tracey Dowdeswell \\ York University, Toronto
}

\begin{abstract}
Immanuel Kant's Cosmopolitanism has come to stand alongside Political Realism and Liberal Internationalism as one of three broad theories of ethics in international relations. Yet Cosmopolitanism has been subjected to criticisms that the universal norms identified by Kant - including such norms as hospitality, reciprocity, and publicity (transparency and free political participation) - are Western and Eurocentric in nature, incompatible with cultural pluralism, and lack the justification and legitimacy for the broad-based consensus required for a Cosmopolitan political sphere to emerge among the world's diverse peoples. This paper seeks to address these criticisms of Cosmopolitanism by studying examples of Cosmopolitan norms in action. These examples have been drawn from diverse regions around the globe to represent self-organized, 'self-legislating', civil societies that have themselves developed the rules that guide their behaviour and the terms of their discourse in the absence of a centralized governing authority. It is hoped that this approach will contribute to this ongoing debate by demonstrating that Cosmopolitan norms can be found in a diverse array of human communities and cultures, that Cosmopolitan norms are not only compatible with pluralism, but are instrumental in its success and vitality, and, finally, that the flourishing of such civil societies shows that the adoption of Cosmopolitan norms are strongly correlated with successful outcomes and well-being.
\end{abstract}

The social relations between the various peoples of the world, in narrower or wider circles, have now advanced everywhere so far that a violation of Right in one place of the earth, is felt everywhere. Immanuel Kant, Perpetual Peace, p. 31.

My father said the whole world is one big chain. One little part breaks and the chain is broken and it won't work anymore.

Johan, 17-year old Dutch rescuer, as recounted to Samuel Oliner, p.142

\section{Kantian Cosmopolitanism}

In 1795, Immanuel Kant argued in his essay, Project for a Perpetual Peace: A Philosophical

Sketch that humanity could solve the problem of violence and war though a political

federation, grounded in universal moral principles, of all the peoples of the earth - an idea that has come to be known as Kantian Cosmopolitanism. Kant's Cosmopolitanism is based upon universal and fundamental moral principles, the first of which is that all human beings are part of a universal moral community in which each person is equal in dignity and worth. ${ }^{1}$

\footnotetext{
${ }^{1}$ This raises the question of how the autonomy of children and other vulnerable or incapacitated persons is to be incorporated into a participatory political framework, a topic of great complexity and which is outside the scope of this paper. In short, my view is that the participation of vulnerable persons sits uneasily within prevailing liberal conceptions of autonomy and politics, and that special attention must be paid by other members of the community to duly consider the interests of such persons and to facilitate their engagement. 
For Kant, the public, political, sphere must be consistent with morality. This occurs when all individuals are treated as morally autonomous ends in themselves, when engagement in the public sphere is founded upon the critical and free exchange of information and ideas, when we each consider the interests of each member of society, and in which each member of society is free to engage.

Cosmopolitanism has come to stand alongside Political Realism and Liberal Internationalism as one of three broad theories of ethics in international relations (Atack 2005, p. 1). Kant's Cosmopolitanism has been subjected to three main criticisms: first, that the universal norms identified by Kant lack justification and are Western and Eurocentric in nature (Atack 2005, p. 16; Rawls 1993, p. 65); second, that normative principles are customary in that they are interpreted and applied in local discursive spheres, shaped by social and cultural factors, and that the principles each community develops have no meaning for outsiders (Dower 1998, p. 23; Rawls 1993, p. 80); and third, that jettisoning self-interest in favour of Cosmopolitan norms, such as hospitality and reciprocity, would place too great a burden on individuals and communities; considering the needs of others is considered a heroic virtue, and not a civic necessity (Honneth 1997, p. 167). Kant's principles, it is argued, lack the justification and legitimacy required for the broad-based consensus necessary for a Cosmopolitan political sphere to emerge among the world's diverse peoples.

This paper seeks to address these criticisms of Cosmopolitanism by studying examples of Cosmopolitan norms in action. These examples have been chosen to represent self-organized communities, communities that have themselves developed the rules that guide their behaviour and the terms of their discourse in the absence of a centralized governing authority. They have also been drawn from a diverse array of human communities throughout the world, including village panchayats in India, farmers and coastal fishers in diverse regions of the globe, as well as rescuers in Nazi-occupied Europe. It can be shown that self-organized and self-legislating civil societies employing Cosmopolitan norms are effective in meeting their goals, adapting to change, reducing conflict, and promoting the well-being of the community's members. It is hoped that this empirical evidence will assist in demonstrating that Cosmopolitan norms can be found in action in a diverse array of human communities and cultures; such norms are not merely the products of Western liberal societies, but are universal characteristics of thriving civil societies. This challenges the view that Kantian norms are remote from the concrete realities of social life; rather, Kant was recognizing basic 
organizing principles of social life that are central to civic engagement and political participation, and that have long been known to and valued by diverse peoples around the world. Examining such communities can show that Cosmopolitan norms are not only compatible with pluralism, they are instrumental in its success and vitality. Finally, the flourishing of such communities shows that Cosmopolitan norms are not burdensome for individuals and communities; on the contrary, Cosmopolitan norms are highly correlated with successful outcomes and well-being. This will open the way for a discussion of how Cosmopolitan norms can be given their full effect in larger and more complex forms of social organization.

\section{Cosmopolitan Norms in Perpetual Peace}

Kant commences his work with a vision of the nature and purpose of human life, beginning with the workings of nature (Kant 1796, p. 31), and the fact that humanity comprises a single species (ibid., p. 29). We are all members of the same species, we all share the Earth, and we must live in proximity with one another. We all have an equal right to profit by the Earth in common, an equal claim to use its resources (ibid., p. 28). ${ }^{2}$ Kant describes this as:

the right that all men have, of demanding of others to be admitted to their society; a right founded upon that of the common possession of the surface of the earth, whose spherical form obliges them to suffer others to subsist contiguous to them, because they cannot disperse themselves to an indefinite distance, and because originally one has not a greater right to a country than another... [Though we are divided] the ship and the camel, that vessel of the desert, reestablishes the communication and facilitate the right which the human species all possess, of profiting in common by its surface. (Ibid., p. 28-29)

Kant describes this as the 'natural right' we all have to establish communication with inhabitants of other countries and lands (ibid., p. 29) - to communicate, to form part of its 'general will', to 'profit in common' by its resources. ${ }^{3}$ Kant thus offers a vision of a right, founded in nature, in our common heritage as a species, our common biology, and our

\footnotetext{
${ }^{2}$ Do prisoners, who are removed from society and deprived of civil and political participation under the law, also possess this right? I would analyze this problem by first noting that such deprivations are prima facie immoral, and that any deprivation of right must be carefully justified for each individual by reference to legitimate moral principles. Even in those cases in which incarceration is morally justified, we must give special consideration to the needs and interests of prisoners as vulnerable persons, and ensure that the living conditions and the social needs of those persons whom we incarcerate meet the standards required by morality.

${ }^{3}$ Of course, 'profiting in common' refers to the egalitarian nature of our right, and not to the amount of profit that we are permitted to extract from nature, or to the obligations we have to the environment and to other living creatures. These issues are addressed by Elinor Ostrom's work, discussed briefly below, which refutes the 'Tragedy of the Commons' and shows instead that human communities operating under Cosmopolitan norms are less likely to degrade natural resources, more likely to preserve them, and are more respectful of the natural environment.
} 
common history, in which each of us are to count as equal members of the human community. Kant sums up this idea by the term hospitality.

Hospitality has been taken by many commentators to refer to an acceptance of strangers, the importance of travel, and an acquaintance with foreign cultures as being the hallmarks of a Cosmopolitan worldview (van Hooft 2009, p. 12-13). Yet we must not allow the definition of 'hospitality' as mere kindness to strangers or an interest in diversity to obscure the deeper meaning of the term, and its origins in the ancient custom of hospitium, which involves care and concern in meeting the needs of each person and welcoming them into our community (a definition better expressed by the modern derivations 'hospital' and 'hospice' ${ }^{4}$ ). Here, Kant expresses a universal and equal entitlement of all persons to the society of others and the resources of the Earth which we inhabit together (Kant 1796, p. 28).

Kant's vision of human life is rooted simultaneously in the universality of humanity as well as the complexity of human life, which provide the foundation for moral universalism. The connections between humans on a global scale are too robust to be denied, and this gives rise to Kant's famous maxim that 'a violation of right in one part of the world is felt everywhere' (ibid., p. 31). At the same time, the diversity and complexity of our ever-changing circumstances and the challenges we face provide the foundation for Kant's deontological moral philosophy. For Kant, a consequentialist moral outlook - one that focuses on outcomes rather than moral actions and values - can never work because we can never know enough to make consistently reliable predictions about the future:

[R]eason is not sufficiently enlightened, in order to embrace the entire series of predetermining causes; the knowledge of which would alone enable it to foresee with certainty the happy or unhappy effects, which, according to the mechanism of nature, must result from human actions (Ibid. p.47).

We should not focus on outcomes, then, as we can never be sufficiently certain what those outcomes will be. This is a vision of human life as complex, non-linear and radically indeterminate, and which thus requires Reason to understand and to grapple with its manyfaceted problems. This describes the role played by the self-legislating individual elucidating a priori moral principles through the exercise of pure practical reason. It is only through derivation from pure practical reason that this imperative is a categorical - universal and $a$

\footnotetext{
${ }^{4}$ In many communities, the exemplary treatment of guests and the special obligations we have to them is one of the core values of society - values which are not always fulfilled to the same extent in our modern institutions.
} 
priori - moral judgement. Kant viewed consequential imperatives as being hypothetical, determined by personal and subjective factors, and thus incapable of directing moral judgement or determining moral ends. 'Good outcomes' are ultimately of only subjective value, and particular to the subject in question. In many cases, outcomes are as indeterminate and elusive as they have always been, and our assessment of probable future events descends into pure speculation; this is true no matter how accurately utility can actually be quantified. The quantitative and reductionist Reason of Jeremy Bentham, in which moral outcomes are governed by the logical algorithms of utility operating in the clockwork-universe, is sometimes misused to blind us to this subjectivity, and it is this misapprehension which made Utilitarianism the pre-eminent moral theory of Modernism.

Kant posits that general will results from the exercise of practical reason on the part of members of the collectivity, in a process that we would think of today as constituting an emergent social phenomenon (ibid., p. 17). Modern definitions of emergence characterize emergent properties as systemic features of complex adaptive systems, which cannot be predicted or known despite a thorough knowledge of the features of and the laws governing the parts (Stanford Encyclopedia of Philosophy). Kant described the general will in a similar fashion, not a sum or balance of the volitions of the individual members of society, but those volitions taken 'by the concert of all' (Kant 1796, p. 48). It is the collective unity of the will of all, not of 'dispersed individuals, but the organs by which they cooperate as a body' (ibid.). The general will thus emerges from a public discourse founded upon principles of morality. The public discourse that produces the general will is one that is founded upon the exercise of practical reason, justice, and 'enlarged', 'unprejudiced' thinking (Kant 2007, p. 160). It is 'laboriously to consider of convincing arguments' and spending time in 'listening to objections' (Kant 1796, p. 54). It requires that we think from the standpoint of everyone else (Kant 2007, p. 160). The more we aim only at a given end in view, the less likely we are to achieve it (Kant 1796, p. 60). Politicians, in particular, are not to pay attention to the material ends which the State seeks (ibid., p. 62). States must reject considerations such as material ends, future consequences, prudence, and the seeking of self-interest, for these are rejections of morality (ibid., p. 46). Instead, Kant provides the maxim to 'Seek first the reign of pure 
practical reason and its justice and your end will necessarily follow' (ibid., p. 60 [emphasis in original]). ${ }^{5}$

\section{Modern Interpretations of Kantian Cosmopolitanism}

The horrors of the two World Wars and the failures of Political Realism thus exposed led to a number of international efforts that might be termed broadly Cosmopolitan, including the Kellogg-Briand Pact of 1928 that outlaws war as an instrument of national policy (a treaty which has been ratified by most States). The prosecutions at Nuremberg, the Universal Declaration of Human Rights, and the post-war Refugee and Genocide Conventions also express many of the humanist and Cosmopolitan norms that resurfaced in the wake of World War II. Modern debates and criticisms of Cosmopolitanism focus on the tensions between the universalism demanded by Kant and the realities of political pluralism, the nature of publicity and its relationship to the general will, and the notion of reciprocity - the Kantian ideal that each person think from the standpoint of everyone else.

\section{Universalism versus Pluralism}

Kant's moral universalism has been critiqued on a number of grounds. Erskine, for example, states that 'claims of impartiality in moral reasoning behave as no more than a façade for the cultural and political imperialism of those with power' (Erskine 2002, p. 477). Robert Pinsky has argued, along with Michael Walzer and John Rawls, that Cosmopolitan principles are really the parochial ideals of a Western upwardly mobile managerial class (Pinsky 2002, p. 85). Rawls states that universal ideals and a belief in individual autonomy are 'particularly liberal or special to our Western tradition' (Rawls 1993, p.69), and would not be accepted by non-liberal societies; imposing them would violate core liberal principles of pluralism and tolerance (Rawls 1993, p. 80). Cosmopolitan norms of human rights, in so far as they are accepted, have been conceived as a kind of 'thin' morality - the very basic rights and standards of conduct upon which we can all agree. For Rawls, pluralism means that the

\footnotetext{
${ }^{5}$ In an earlier work, Idea for a Universal History with a Cosmopolitan Purpose, Kant posited that history was progressing towards a 'Cosmopolitan civil society which can administer justice universally' (1784, p.20). 'End', read in this way, refers not to the particular ends we may aim at daily as the fulfilment of our self-interest, but the ultimate political end brought about by a universal Cosmopolitan constitution. Kant posited that this would emerge as a result of the fulfilment of individual striving for pure practical reason: '[I]f [history] examines the free exercise of the human will on a large scale, it will be able to discover a regular progression among freely willed actions. In the same way, we may hope that what strikes us in the actions of individuals as confused and fortuitous may be recognized, in the history of the entire species, as a steadily advancing but slow development of man's original capacities' (17). Kant, I. 1784, 'Idea for a Universal History from a Cosmopolitan Point of View' in Brown, G.W. \& Held, D. (eds), The Cosmopolitan Reader, Polity Press, Cambridge, pp.17-26.
} 
general will is a matter of overlapping consensus, 'the bedrock beyond which we cannot go' (Rawls 1993, p. 78), and in order to produce even this very minimum standard of morality, we must be prepared to water down our ideals considerably (McCarthy 1997, p. 206).

Other critics have argued that universal norms deny the fact that politics, democratic participation, and moral norms flourish in local communities, that they are embedded, and that they derive their moral and normative force from 'the emotional pull of love of hearth and home' (Barber 2002, p. 30). Moral reasoning is 'necessarily situated, embedded, and embodied' (Erskine 2002, p. 572 [emphasis in original]). Local community is where democracy and civic patriotism flourish, and not in abstract and intellectual universals (Barber 2002, p. 31). Amy Gutmann argues that we need to teach and think about justice in its concrete form as part of the nation state, for the 'world' is not a community in the relevant sense; Cosmopolitan universals are too abstract and intellectual to command any allegiance or normative force (Gutmann 2002, p. 66). Gertrude Himmelfarb similarly argues that everyone must belong to a polity, a community, for we are inherently social. She claims that '[w]hat cosmopolitanism obscures, even denies, are the givens of life: parents, ancestors, family, race, religion, heritage, history, culture, tradition, community - and nationality' (Himmelfarb 2002, p. 77).

In response to these criticisms, Martha Nussbaum argues for a cosmopolitanism that transcends divisions and extends to all human beings (Nussbaum 2002). Justifications for human rights upon which everyone can agree must not depend upon a particular cultural or metaphysical conception (van Hooft 2009, p. 73). David Braybrooke in his Natural Law Modernized draws upon developmental psychology, in which he finds that human beings begin life in bonds of mutual attachment and affection, and argues that this is crucial in developing the reciprocity that underlies the general will (Braybrooke 2003). For Nussbaum and Braybrooke, love of humanity is not a stage of development that comes later, after one learns to love family, then community, then nation, but that these are all manifestations of the love of humanity that is the core of human cognitive and social development and which is present all along. We do not learn to love others who are distant from us; we learn to become divided from them. ${ }^{6}$

\footnotetext{
${ }^{6}$ Here, one might reference Henri Tajfel and his famous 'minimal group' experiments, in which he found that simple categorization, for example based on a preference for one abstract painting over another, was enough for subjects to demonstrate a preference for 'in-group' over 'out-group' members (see for example, Henri Tajfel
} 


\section{Publicity and the General Will}

The general will emerges from the individual exercise of practical reason. Practical reason stems from the moral autonomy of self-legislating individuals as ends in themselves. This is 'the idea of persons as ends in themselves, the ideal (i.e., idea in individuo) of a kingdom of ends as an association of free and equal rational beings under universal laws they give to themselves' (McCarthy 1997, p. 203). Practical reason is embedded reason; it is the critical thinking, reflecting, and evaluating that we use to form judgements and guide action in our everyday lives. Practical reason is embedded in language and culture, in our particular time and place in history; it involves a self-awareness of our preconceptions, prejudgements, preunderstandings that inform any rational undertaking (McCarthy 1997, p. 203), and our willingness to confront and challenge them when we appreciate different points of view, when we hear good ideas, when the facts change. To conceive of the general will as an emergent phenomenon, and the exercise of practical reason as an embedded an inherently public and social activity, bridges the inherent tension between the individuals as ends-inthemselves and individuals as part of a collectivity.

Bohman argues that the general will emerges from the exercise of practical reason when it forms part of an engaged and self-referential public discourse. He states,'[t]he public sphere is not merely a collection of spaces or forums, such as salons, clubs, theaters, union halls, and other meeting places; nor does it consist merely of a set of formal procedures or institutional rules' (Bohman 1997, p. 189). It is a part of a community that is self-understanding, selfreferential, and self-critical (ibid.). This self-reflexivity is part of the dynamic public process by which a community constructs a sense of itself by forming and testing its attitudes and beliefs (ibid., p. 190). It is never a given, never an end that converges upon a single rational outcome - 'for Kant, it is always and forever a task' (McCarthy 1997, p. 202).

Kant's idea of 'publicity' is by its very nature free from coercion and authority: communicative success in the public sphere can only arise when the audience is unburdened by assumptions about who is authorized to make claims (Bohman 1997, p. 184). Public

1981, Human Groups and Social Categories, Cambridge: Cambridge University Press). While Tajfel's work shows the ease with which we are able to form and prefer in-group over out-group attachments, it must be remembered that Tajfel also found that out-group devaluation - and even more so, out-group harming - are not inevitable consequences of in-group identification - a position which is supported by the Oliner's research on Holocaust rescuers, discussed below. 
speech must necessarily be free from restrictions, and assent and dissent must be expressed by free and equal participants (ibid.). Kant posited that the only real check on violations of right is when they can be publicly acknowledged, and the rights and claims of the dispossessed can be recognized and defended by public opinion (ibid., p. 182). This is precisely what enables us to 'form justifications that anyone may accept' (ibid., p. 184). The audience is necessarily unrestricted and inclusive. 'Such an audience,' Bohman argues, 'is thus more, rather than less, pluralistic and diverse in its opinions' (ibid.). All members of a community participate in public discourse, and a community member is anyone who wishes to be admitted, and this provides the surest foundation for a democratic global discourse.

\section{Reciprocity: Thinking from the Standpoint of Everyone Else}

David Held understands the core values of Cosmopolitanism to be moral egalitarianism and reciprocal recognition of the equal moral respect of every person (Held 2010, p. 230). This idea has sometimes been summed up as the norm of 'reciprocity', of thinking from the standpoint of everyone else. For Nussbaum, this means that 'we owe it to other human beings to try to understand their ways of thinking', to allow one's judgements to be informed thereby, and revised accordingly (Nussbaum 1997, p. 36). The notion of reciprocity is necessary for the general will to emerge - not by a consensus upon some single rational opinion (Bohman 1997, p. 186), but from a particular kind of discourse in which the interests of each have been duly considered. In this discourse, shared beliefs are thus constantly revised as new perspectives are added, new facts come to light. Pluralism and the dynamic nature of our social spheres require a constant re-evaluation of our shared beliefs. This involves listening, understanding, an obligation of expression and articulation, and a sense of humility and openness to new ideas. The examples discussed below show that this is not only a liberal ideal, as it is practiced in numerous 'liberal', 'non-liberal', and 'traditional' societies. ${ }^{7}$

It is often assumed that identity-forming relationships, such as we have with family, friends and colleagues, or as co-members of larger ethnic, religious and social groups, are parochial and necessarily entail the exclusion of others (van Hooft 2007, p. 92). As van Hooft sums up this argument:

\footnotetext{
${ }^{7}$ I question whether these are relevant categories for classifying societies: reciprocity, hospitality, the freeexchange of information, and participation are core values in many 'traditional' societies, whereas they often fail to come to full fruition in many 'liberal' ones.
} 
In so far as I draw my identity from such groupings I shall care about their members. The key to this ethic is that I am motivated to help others not out of a sense of duty, but out of concern for them. The problem with this ethic is it does not seem to be universal. It apparently confines itself to those with whom I have the relevant kind of relationship... Caring does not seem to have the global scope espoused by cosmopolitanism (ibid.).

While van Hooft argues that reciprocity cannot be extended beyond parochial ties, Appiah argues that caring and concern are not only parochial, they are uncertain and contingent bases on which to uphold rights and human dignity for the oppressed (ibid., p. 95).

It is with the goal of shedding light on these issues that I now turn to empirical studies of embedded Cosmopolitan norms in action, examining the ways in which self-legislating, selforganized communities constructed the general will, handled the exchange and publicity of information, defined community membership, and extended reciprocity, even to those who did not share the same religion, nationality, or ethnicity. Cosmopolitan norms can be seen to be embedded in these forms of social interaction, and we might ask how this can lay the foundations for a truly moral civic life, one that can foster linkages between communities at greater levels of scale and complexity, as imagined by Kant in his ideal of a universal federation of peoples.

\section{Public-Choice Theory and Self-Organized Communities}

Elinor Ostrom and her colleagues have studied numerous communities and the challenges they face in establishing collective action, trust, and common rules in the management of common pool resources, such as fishing grounds, irrigation systems, and forests. Her work has shed light on public choice theory in economics, work for which she was awarded the Nobel Prize in 2009. Ostrom et al. view communities managing common pool resources as complex adaptive systems. In complex situations, optimal solutions can be difficult to arrive at, yet many communities establish satisfactory rules to govern their common behaviour (Ostrom et al. 1994, p. 325). Ostrom examined how such communities established their own rules, built trust and a sense of legitimacy regarding self-generated rules, monitored compliance and sanctioned rule-breakers. Ostrom's research began in the laboratory, where she demonstrated, through experiments in non-cooperative game theory, that in common-pool resource dilemmas where the individuals do not know one another, cannot communicate effectively, and thus cannot develop agreements, outcomes were much poorer than those predicted by standard rational choice theories (ibid., p. 319). In settings in which rational choice and individual self-interest were emphasized and rewarded, Ostrom et al. found that 
'others are likely to over-appropriate, under-provide, and/or engage in high levels of conflict about assignment and technological externality problems'; instead, simply allowing individuals to talk to one another produces a significant change in behavior concerning cooperation, rule-generation, trust and, ultimately, better outcomes (ibid.). As Ostrom demonstrated through her experiments in cooperative game theory, even the simple act of communication can facilitate the emergence of shared norms that improve outcomes for all participants. Successful communities went further, and demonstrated the values of reciprocity, inclusiveness, and the free exchange of information, and these allowed legitimate self-generated norms to emerge that were able to reduce conflict, meet the needs of community members, and avoid degradation of the common pool resource. The principles which these cultures embody and which make their local systems of common-pool resource use robust are thus the same principles that Kant identified as enabling Cosmopolitanism to flourish on the global scale. If it can be shown that Cosmopolitan principles enable the flourishing of local communities, then we can begin to inquire into how such communities can link together to facilitate Cosmopolitanism in larger and more complex - even global social groupings.

Edella Schlager collected data from several case studies of coastal fishing communities that faced a common pool resource dilemma. These fisheries were drawn from a diverse array of communities from around the world, including North and South America, Europe, Asia, Africa and India (Schlager 1994, pp. 255-6). The first issue facing fishers was whether to make their own individual response to the fishing strategies adopted by others, or to organize with other fishers so as to change the structure of the rules affecting fishing activities (ibid.). The individual, unorganized state is similar to the non-cooperative game theory experiments discussed above in which self-interest was rewarded and communication with others cut off, and this led inevitably to the degradation of the common pool resource (Blomquist 1994, p. 293).

Relationships based on reciprocity, with each member thinking from the standpoint of everyone else, such as the fishing community in Alanya, Turkey, were more successful in generating rules that assigned resources equitably and reduced conflict (Schlager 1994, p. 263). Fishers who were successful in solving assignment problems were those who understood how their actions might affect each other (ibid., p. 251). Opportunistic individual behaviour is seen by such fishers as undesirable in that it destroys the possibility for the gain 
of all (ibid.). In studying performance in irrigation system users, Tang similarly found that 'individuals who have lived together for some time are able to develop various social networks and reciprocal relationships with one another in various social arenas. Knowledge about these networks and relationships is shared by members of the community. It is often difficult for outsiders to identify these networks and relationships' (Tang 1994, p. 239). Reciprocity worked best when there were repeated encounters under similar circumstances among the fishers, and an information network arose to gather and exchange information and to identify and negotiate rules (ibid.). Relationships based upon reciprocity thus generated rules that were seen as being legitimate, that satisfied the community members' needs and that were more readily followed.

Community members build trust and extend reciprocity through the use of personal heuristics - stories and maxims that describe the rules and guide right conduct within the community's system of norms - as well as measured reactions, and the use of mild sanctions that progressively increase in their sanctioning power (Ostrom et al. 1994, p. 327). Individuals operating under norms of reciprocity, cooperation, and the free exchange of information and ideas 'achieve more than predicted by non-cooperative game theory as traditionally understood' (ibid., p. 328). On the other hand, where individuals have no expectations of mutual trust and no means of building trust through communication and continued interaction, or where mistrust is already rampant and the communication and interactions do not reduce the level of distrust, then solutions are unlikely (ibid.). Reciprocity and hospitality can be far more powerful in guiding conduct than a centralized coercive authority. Ostrom et al. found that communities plagued by conflict and mistrust suffered from higher levels of conflict as well as resource degradation. In this way, communities that adopted Cosmopolitan norms suffered fewer of these burdens than those who did not. Ostrom et al. also demonstrate a complex relationship between self-organized communities and outside centres of power. Where individuals are prevented from creating rules and establishing their monitoring and sanctioning, and when those 'who are preyed upon cannot develop sanctions against their predators, the likelihood of achieving higher outcomes through their own efforts is low' (ibid.). In such cases, outside intervention to restrain oppressive power may be required.

Arun Agrawal conducted a field study of six villages in the Almora district of Uttar Pradesh, India, and their management of the common pool resource of the local forests, called panchayats. All villages were subject to the same centralized laws and administrative rules, 
yet within this framework, each had adapted their own rules to the local conditions (Agrawal 1994, p. 271). Local users were better able than central authorities to craft rules to govern the use of grazing and fodder extraction from the forests, as they have greater information about themselves, their needs, and the resource, including how to match demands on the resource with its regenerative capacity (ibid., p. 273).

The successful management of panchayats depends upon communication, the legitimacy of the norms generated, and successful monitoring and sanctioning of rules. When rules are not monitored or enforced, and violations are not sanctioned, then rules become meaningless guides to behaviour. This often occurred in cases in which government officials were charged with monitoring and sanctioning (ibid., p. 275). When monitoring is left solely to outside intervenors, such intercession runs the risk of disrupting the local system. Guards are not numerous enough to catch very many rule-breakers, and they are easily corruptible (Ostrom et al. 1994, p. 326). Successful panchayat monitoring regimes involved all of the members of the community, including guards and government officials; guards under the direction of local officials brought rule-breakers before the entire village to confess their transgression and receive a penalty imposed by the villagers. The real success of this strategy lies in what Agrawal terms the 'closed-loop' created among all monitors in the system: bureaucratic officials direct the guards, who monitor the resource users, who in turn monitor the guards and direct the officials as to what penalties are to be applied (Agrawal 1994, p. 276). No formal or legal powers existed to maintain the authority of this system or to enforce the penalties exacted from individual rule-breakers; rather, legitimacy depended upon the recognition of the villagers, who were themselves instrumental in crafting and monitoring the rules (ibid.). Closed-loop monitoring systems such as this one are able to make successful linkages with the broader administrative regime, and embody reciprocity, publicity, and participation. It therefore appears that such systems can be extended to communities larger in scale than that of the village. ${ }^{8}$

Not all villages were equally successful. In one village, Brahmins dominated the forest use. No Brahmin was ever reported to have violated a rule; all penal activities were enforced against the lower castes, who themselves were not involved in crafting or monitoring the rules, and who determined that the rules had no legitimacy (ibid., p. 276). Forest resources

\footnotetext{
${ }^{8}$ One such example is Police Complaints Commissions which, even when they allow for some independent monitoring, close off public participation in fact-finding and sanctioning.
} 
went disproportionately to the higher castes (ibid.). The result of this inequity was high levels of forest degradation and inter-caste conflict (ibid.). Forest-use systems based upon equity and the participation of the whole village showed lower levels of conflict and lower rates of forest degradation (ibid.). These villages collected more money in fines, and were more profitable overall (ibid.). Successful management depends upon communication, inclusivity, and the legitimacy of the norms generated. There were class differentials in the other villages, as well, but this did not become a site of struggle over power and resources, showing that inclusive participation and social difference can co-exist comfortably.

Ostrom et al. affirm the importance of forming linkages between groups, and between local groups and larger regional authorities, to exchange information and to share resources. Encouraging federations of self-organized common pool resource users to exchange information about their experiences 'may be more important in enhancing the efficiency and equity use patterns than attempting to design and enforce uniform rules devised by an external authority' (Ostrom et al. 1994, p. 326). The free exchange of information and ideas worked well at the local scale, as did the building of relationships of reciprocity, and these achievements can perhaps be brought to be effective at greater levels of scale within a broader system.

\section{Rescuers in Nazi-Occupied Europe}

On 27 January 2008, Yad Vashem, The Holocaust Martyrs' and Heroes' Remembrance Authority, opened in New York the first exhibition of Besa: A Code of Honor - Muslim Albanians Who Rescued Jews During the Holocaust. Besa is the work of American photographer Norman Gershman who spent four years in Albania photographing Muslims who had rescued Jews during the Holocaust. Holocaust rescuing communities are expressions of Kant's highest ideal of Cosmopolitan recht - that of hospitality. Albania is unique among Holocaust rescuing communities in that nearly all the Jews living within Albania's borders were saved, not only native inhabitants but also the many refugees who had fled persecution elsewhere (Shendar \& Shaechter 2008, p. 12). The Albanians' rescuing activities stemmed from a deep-seated belief in 'Besa', a code of honour, hospitality, and moral egalitarianism, passed down through the generations. Herman Bernstein, the United States Ambassador to Albania stated in 1934, 'There is no trace of any discrimination against Jews in Albania, because Albania happens to be one of the rare lands in Europe today where religious 
prejudice and hate do not exist, even though Albanians themselves are divided into three faiths' (Gershman 2008).

Norman Gershman's photographs of Albanian rescuers, displayed at the Besa Exhibition, are infused with the values of family, humanity and hospitality. Rescuers stand in front of their homes, doors open wide, sometimes with shoes strewn across the mat, welcoming all visitors. They hold out cups of tea, or lovingly display photographs of departed relatives, in this small and culturally homogenous, deeply religious and deeply cosmopolitan society, to express Kant's ideal of the law of hospitality during the dark days of the Holocaust. Rescuers embodied Kant's ideal of moral universalism - that all persons are ends in themselves and of equal worth - as well as reciprocity, Kant's counsel that we think from the standpoint of everyone else. Rescuers demonstrate how cultural pluralism and strong ties to local norms and customs are not only compatible with moral universalism and egalitarianism, but depend upon it for the embodiment of moral values within those norms and customs. Rescuers also demonstrate the truth of what Kant argued in Perpetual Peace: that when political discourse is subordinate to morality, peace among peoples can be achieved.

The study of Holocaust rescuers demonstrates how local, even isolated, individuals and communities embodying Cosmopolitan norms can link-together to form networks that span cultural, linguistic and religious divides which, by the end of the war, grew to cover much of Europe. The growth and stability of the rescuer networks occurred under conditions of extreme hostility and deprivation. Samuel and Pearl Oliner undertook a large study of rescuers in Nazi-occupied Europe, individuals who had risked their lives, and laboured under extremely hostile conditions, to help others (Oliner \& Oliner 1988). To be considered a rescuer, candidates had to be motivated by humanitarian considerations only, risked his or her own life, and received no remuneration of any kind. The Oliners interviewed 406 rescuers, 150 survivors who had been rescued, and 126 non-rescuers (ibid., p. 2). The Oliners found that rescuing was based on the values the rescuers held, and not on situational or demographic factors. Situational factors did not distinguish rescuers from bystanders; rescuers cut across all classes and had varying access to resources, with some being very poor (ibid., p. 128). Nor did access to information, or pre-existing relationships with Jewish persons affect rescuing. It was not the knowledge people had, but the significance they attached to it that was the defining difference between rescuers and bystanders (ibid., p. 123). Rescuers viewed the Nazi atrocities from the point of view of those who were persecuted, 
and had a deep emotional response to injustices committed against even those persons whom they did not personally know. Rescuers saw humanity as a universal moral community from which no one is excluded; they felt and interpreted the persecution from the point of view of the persecuted; they demonstrated not only reciprocity, but deep compassion. Rescuers 'defy what we think we know about human nature: that we act in the service of our own selfinterest' (Schulweiss 1988, p. viii).

Rescuers held values of egalitarianism and inclusiveness. These values were instilled in early childhood from parents and caregivers, and are what prompted and sustained rescuers' involvement (Oliner \& Oliner 1988, p. 142). Universalism and egalitarianism - never looking down on people because of who they were - were values rescuers said they learned from their parents, and this distinguished them from bystanders (ibid., p. 143). Rescuers held values of inclusiveness, which was defined in the study as a predisposition to regard all peoples as equals and to apply similar standards of right and wrong to them without regard to social status or ethnicity (ibid., p. 144). Rescuers' caregivers had not communicated negative or stereotyped comments about other peoples in general (ibid., pp. 153-5). Rescuers were significantly more likely than bystanders to believe that ethical values were universal, and were to be applied to all human beings as part of a universal moral community. As the Oliners state, 'what is striking about a large percentage of rescuers is the consistently universalistic orientation, exemplified not only in the values they recall learning from their parents but also in the reasons they give for rescuing Jews' (ibid., p. 166). Whereas rescuers were marked by extensivity, bystanders were marked by constrictedness, by an 'ego that perceived most of the world beyond its own boundaries as peripheral'; bystanders were more centered on themselves and their own needs, and they were less conscious of others, less concerned with them, and exhibited the dissociation, detachment and exclusiveness that are the hallmarks of a constricted person (ibid., p. 186). A tendency to privilege only the interests of ourselves and those with whom we have a close personal relationship is neither an inevitable nor a ubiquitous human orientation. Parochial affiliations are not a consequence of bonds of attachment, but a consequence of their absence. The values rescuers emphasized included pity, compassion, concern, affection, values that have a strong emotional component, and which in turn come from emotional bonds of attachment (ibid., p. 168). Rescuers felt the suffering of a stranger to be as much their responsibility as that of a friend, and their care extended well beyond their close circle (ibid., p. 169). 
The Oliners' study lends empirical support to the idea proposed by Martha Nussbaum and David Braybrooke, that strong bonds of attachment in early childhood are the key to developing a universal and egalitarian moral outlook. Rescuers reported stronger childhood attachments than bystanders, and this was strongly correlated with rescuers developing greater extensivity as adults, i.e. they felt stronger bonds of attachment than bystanders with all people; rescuers did not restrict their attachments only to their own families (ibid., p. 173). Supportive and close parental homes propelled rescuers towards extensive relationships with others, and this included even those with whom the rescuers did not have a personal relationship (ibid., p. 183). Rescuers also reported a greater belief in the value of attachment - a belief in the value of personal relationships and caring for the needy (ibid., p. 144). Sazan Hoxha's father, Nuro Hoxa, sheltered four Jewish families through the war. He told them, 'Now we are one family. You won't suffer any evil. My sons and I will defend you against peril at the cost of our lives' (Gershman). Sazan explains, 'As devout Muslims we extended our protection and humanism to the Jews. Why? Besa, friendship and the holy Koran. This is a picture of my Father that I hold close to my heart' (ibid.).

Universal and humanist moral principles were thus compatible with culture and religion, as well as a love of country and feelings of patriotism. Rescuers expressed strong feelings of patriotism, yet this did not lead them to exclude those of a different nationality. The majority of rescuers and non-rescuers said that they were very patriotic (65 and 68 percent respectively), and only a minority in both groups reported being slightly or not at all patriotic. Politics seemed to play a small role in the views of both rescuers and non-rescuers, although rescuers and their parents were slightly more likely to belong to democratic political groups (ibid., p. 159). A universal ethical orientation was found to be consistent with feelings of patriotism, and in rescuers a love of one's own country stood quite comfortably alongside a love of humanity as a whole.

Support groups tended to grow up among small groups of like-minded persons, often beginning with family members, extending to other relatives, and to supportive civic groups, such as schools, religious congregations, political and resistance movements, and even sporting clubs (ibid., pp. 94-97). These informal networks were self-organized and selfgoverning. As the Oliners state, 'informal networks were not governed by rules and regulations but were rather the product of emergent cooperative processes. Objectives in such groups were not determined by a remote leadership; rather they emerged in the context of 
needs as participants defined them' (ibid., p. 131). What governed the linkages formed in these networks were the sentiments and behaviours of individuals, the kinds of people they were, their values, and whether they were likely to be supportive (ibid.). The rescuers' shared moral universalism gave rise to an emergent civil sphere that linked disparate individuals into large regional networks that were able to articulate core values and solve practical problems of survival under extremely challenging conditions.

Rescuers and their networks were remarkably successful even under the harsh oppressions of the Nazi occupation. Under extreme tyranny and deprivation of the necessities of life, Polish rescuers sheltered about 450,000 of their Jewish neighbours through the war (Lukas 1989, p. 13). Danish rescuers evacuated 7,200 people to safety in Sweden, and Yad Vashem has authenticated thousands of rescues throughout the occupied territories. Furth has found that there were perhaps as many as 1.2 million rescuers in Poland alone (Furth 1999, p. 227). Millions more supported movements dedicated to rescuing and resistance to the Nazi occupation. The witnessed the end of the war and the liberation of the camps. Their success lies in the lives they saved and the families and communities that continue to flourish as a result, and because they demonstrate to oppressive regimes who would perpetrate inhumanities that the multitude will stand in their way - goals not imagined by the rescuers themselves, but which demonstrate the wisdom of Kant's maxim: Seek first the reign of pure practical reason and its justice and your end will necessarily follow.

\section{Conclusion}

In Perpetual Peace, Kant posited that the key Cosmopolitan recht is that of hospitality - the universal custom of opening one's door to strangers, of offering them shelter and a cup of tea, of accepting them simply as fellow humans, as fellow travelers on this small Earth we all inhabit together, and whose benefits we equally steward. Rescuers demonstrate that this universal moral outlook is neither abstract nor intellectual, that it is embedded in the emotional ties and compassion that we have even for those who are strangers to us, and that it depends for its existence on the 'emotional pull of love of hearth and home' (Barber 2002, p. 31). Rescuers' cosmopolitan outlook did not obscure the givens of life: parents, ancestors, family, race, religion, heritage, history, culture, community (Himmelfarb 2002, p. 77), Besa. On the contrary, it sprang from and was nourished by all of these. Nor did rescuers obscure and deny their nationality, for rescuers were as patriotic as bystanders, and quite patriotic at that. Nor was their universalism and reciprocity a burden for rescuers, despite the hardships 
they faced. On the contrary, they found that articulating the core values of humanity was a source of liberation in the dark days of the Nazi occupation.

Homo sapiens sapiens is a species, and like every species is united by a common evolution, a common biology, a common heritage. Like every species, humanity comprises a complex adaptive system, remarkable in its diversity and capacity for change. Kant sought to elucidate and ground in our common nature the core principles of Cosmopolitan recht which he saw as the constitutional norms of humanity - universal and operative at every level of scale within the system where they serve to guide conduct and justify the rules we choose to govern ourselves. Claims about human nature, the nature of moral decision-making, practical reason, public discourse, and social institutions, are in many ways empirical claims. As such, they need to be justified with reference to empirical data gathered by researchers in the social and natural sciences. As Kersting states, we may have to place our faith in anthropology (and sociology, and psychology, and economics, and so on), but that it is not necessary for us to imagine a 'culture-free', 'culturally-untouched stratum' of interest and rationality in order to imagine the co-existence of universalism and pluralism (Kersting 2002, p. 33). It is precisely within hearth and home and culture that we develop our commitment to moral universalism and our deep appreciation for the dignity and worth of every human being, and which binds us together in a human community. These are the norms which Kant thought that everyone can agree to be bound by, as these norms have for centuries made up what Kersting calls the 'normative grammar' of our social worlds (ibid., pp. 20-1).

It is also here, embedded in hearth and home and culture, that pure practical reason is fostered, expressed, and comes to form the kind of political engagement and public discourse from which emerges the general will. This political space is founded upon morality, and comprises a human commons, a 'normative grammar' from which we all draw as we write the tales that become our particular cultures and our individual lives. Formal and rational instruction have their place, but the kind of education that produces practical reason is embedded in deep emotional bonds of attachment and affection, and is open to all communities - whether we live our lives in a remote village in Albania, a farm in California, a fishing village in Turkey, a panchayat in India, or in the salons and universities of Vienna and Amsterdam. The communities examined in this paper also show us how ethics of universality, hospitality, and publicity underlie a vibrant civil society in diverse cultures. Such ethics, by virtue of their commonality, can form linkages between peoples, linkages that can 
span the divides of language, religion, nationality, and geography. We can indeed look towards this Cosmopolitan ethic if we would take up the challenge that Kant posed more than 215 years ago - to generate a thriving civil society among the world's diverse peoples.

\section{Bibliography}

Atack, I. 2005, The Ethics of Peace and War: From State Security to World Community, Palgrave Macmillan, New York.

Barber, B. 2002, 'Constitutional faith' in Nussbaum, M. \& Cohen, J. (eds), For Love of Country?, Beacon Press, Boston, pp. 30-37.

Blomquist, W. 1994, 'Changing Rules, Changing Games: Evidence from Groundwater Systems in Southern California' in Ostrom, E., Gardiner, R. \& Walker, J. (eds), Rules, Games and Common- Pool Resource Dilemmas, The University of Michigan Press, Ann Arbor, pp. 283-300.

Bohman, J. 1997, 'The Public Spheres of the World Citizen' in Bohman, J. \& Lutz-Bachman, M. (eds), Perpetual Peace: Essays on Kant's Cosmopolitan Ideal, MIT Press, Cambridge, pp. 179-200.

Braybrooke, D. 2003, Natural Law Modernized, University of Toronto Press, Toronto.

Dower, N. 1998, World Ethics: The New Agenda, Edinburgh University Press, Edinburgh.

Erskine, T. 2002, "Citizen of nowhere' or 'the point where circles intersect?' Impartialist and embedded cosmopolitanisms', Review of International Studies, vol. 28, no.3, pp. 457478.

Furth, H.G. 1999, 'One Million Polish Rescuers of Hunted Jews?', Journal of Genocide Research, vol.1, no.2, pp. 227-232.

Gershman, N. 2008, Besa: A Code of Honor - Muslim Albanians Who Rescued Jews During the Holocaust, Yad Vashem Photography Exhibition, http://www1.yadvashem.org/yv/en/exhibitions/besa/introduction.asp, accessed 16 December 2010.

Gutmann, A. 2002, 'Democratic Citizenship' in Nussbaum, M. \& Cohen, J. (eds), For Love of Country?, Beacon Press, Boston, pp. 66-71.

Held, D. 2010, 'Principles of Cosmopolitan Order' in Brown, G.W. \& Held, D. (eds), The Cosmopolitan Reader, Polity Press, Cambridge, pp. 229-247.

Himmelfarb, G. 2002, 'The Illusions of Cosmopolitanism' in Nussbaum, M. \& Cohen, J. (eds), For Love of Country?, Beacon Press, Boston, pp. 72-77.

Honneth, A. 1997, 'Is Universalism a Moral Trap? The Presuppositions and Limits of a Politics of Human Rights' in Bohman, J. \& Lutz-Bachman, M. (eds), Perpetual Peace: Essays on Kant's Cosmopolitan Ideal, MIT Press, Cambridge, pp. 155-178.

Kant, I. 1796, Project for a Perpetual Peace: A Philosophical Sketch, translated from the German, Stephen Couchman for Verner and Hood, Birchinlane, Cornhill, online book by Making of the Modern World, http://www.library.yorku.ca/eresolver/?id=1144229, accessed 16 December 2010.

Kant, I. 2007, Critique of Judgment, Meredith, J.C. (trans.), Oxford University Press, Oxford. Kersting, W. 2002, 'Global Human Rights, Peace and Cultural Difference: Huntington and the Political Philosophy of International Relations', Kantian Review, vol. 6, pp. 5-34.

Lukas, R. 1989, Out of the Inferno: Poles Remember the Holocaust, University Press of Kentucky, Lexington.

McCarthy, T. 1997, 'On the Idea of a Reasonable Law of Peoples' in Bohman, J. \& LutzBachman, M. (eds), Perpetual Peace: Essays on Kant's Cosmopolitan Ideal, MIT Press, Cambridge, pp. 201-218. 
Nussbaum, M. 1997, 'Kant and Cosmopolitanism' in Bohman, J. \& Lutz-Bachman, M. (eds), Perpetual Peace: Essays on Kant's Cosmopolitan Ideal, MIT Press, Cambridge, pp. 25-58.

Nussbaum, M. 2002, 'Reply' in Nussbaum, M. \& Cohen, J. (eds), For Love of Country?, Beacon Press, Boston, pp. 131-144.

Oliner, S. \& Oliner, P. 1988, The Altruistic Personality: Rescuers of Jews in Nazi Europe, The Free Press, New York.

Ostrom, E., Gardiner, R. \& Walker, J. (eds), Rules, Games and Common-Pool Resource Dilemmas, The University of Michigan Press, Ann Arbor.

Pinsky, R. 2002, 'Eros Against Esperanto' in Nussbaum, M. \& Cohen, J. (eds), For Love of Country?, Beacon Press, Boston, pp. 85-90.

Rawls, J. 1993, 'The Law of Peoples' in Shute, S. \& Hurley, S. (eds), On Human Rights: The Oxford Amnesty Lectures 1993, Basic Books, New York.

Schlager, E. 1994, 'Fishers' Institutional Responses to Common-Pool Resource Dilemmas' in Ostrom, E., Gardiner, R. \& Walker, J. (eds), Rules, Games and Common-Pool Resource Dilemmas, The University of Michigan Press, Ann Arbor, pp. 247-266.

Schulweiss, H.M., 1988, 'Forward' in Oliner, S. \& Oliner, P. 1988, The Altruistic Personality: Rescuers of Jews in Nazi Europe, The Free Press, New York.

Shendar, Y. \& Schaechter, S. 2008, 'Besa: A Code of Honor', Yad Vashem Magazine, vol. 48 (Winter 2008), pp. 12-13, http://www1.yadvashem.org/about_yad/magazine/magazine_48/pdf/p12-13.pdf, accessed 16 December 2010.

Stanford Encyclopedia of Philosophy, 'Emergent Properties', Stanford University, http://plato.stanford.edu/entries/properties-emergent/, accessed 20 November 2010.

Tang, S.Y. 1994, 'Institutions and Performance in Irrigation Systems', in Ostrom, E., Gardiner, R. \& Walker, J. (eds), Rules, Games and Common-Pool Resource Dilemmas, The University of Michigan Press, Ann Arbor, pp. 225-246.

van Hooft, S. 2009, Cosmopolitanism: A Philosophy for Global Ethics, Acumen, Stocksfield. 